\title{
REVIEW
}

\section{REGISTERS OF PRESSURE ULCERS IN AN INTERNATIONAL CONTEXT}

\section{Andrea Pokorná1, Simona Saibertová1, Soňa Vasmanská1, Lucie Kubátová ${ }^{2}$, Nina Müllerová ${ }^{3}$, Petra Camprová ${ }^{4}$, Gabriela Šmelková ${ }^{4}$}

${ }^{1}$ Masaryk University, Faculty of Medicine, Department of Nursing, Brno, Czech Republic

${ }^{2}$ Military University Hospital Prague, Surgical Department, Prague, Czech Republic

${ }^{3}$ University Hospital Pilsen, Czech Republic

${ }^{4}$ General University Hospital in Prague, Czech Republic

Received October 19, 2015; Accepted January 25, 2016. Copyright: This is an open access article distributed under the terms of the Creative Commons Attribution International License (CC BY). http://creativecommons.org/licenses/by/4.0/

\begin{abstract}
Aim: The aim of the following review was to search for existing registers of pressure ulcer (PU) incidence operating and collecting data on national level. Design: Type of study - review. Methods: Articles focusing on the subject of national PU registers were searched for by means of a systematic trawl through various databases using relevant terms. The search was limited to articles in English issued between 2010 and 2015 in the electronic databases SCOPUS and Nursing OVID. Articles focused on local datasets or registry as a part of local electronic health records were not included as well as studies which do not describe the dataset or the usability of data collection. Results: In total, six papers were found fulfilling the established criteria. Conclusion: According to information available from the literature review, it was recognised that only one register of PUs currently exists at the national level - the Registry of Ulcer Treatment (RUT) in Sweden. It can be assumed that registers exist in other countries, but that the information is not available on electronic databases. After a detailed inspection of the articles, it appears the information derived from the studies could provide a useful picture of the data that should be collected, and at what time during the treatment period (initial and final assessment of the patients and local symptomatology of the wound/pressure ulcer) it should be collected.
\end{abstract}

Keywords: pressure ulcers, pressure sores, bed sores, pressure injury, decubital lesions, decubitus, register, dataset, review, incidence, prevalence.

\section{Introduction}

Pressure ulcers (also known as pressure injuries, bed sores, pressure sores and decubitus ulcers synonyms) are localised injuries to the skin, underlying tissue or both, usually over a bony prominence, as a result of pressure or pressure in combination with shear. A number of contributing or confounding factors are also associated with pressure ulcers; the significance of these factors is yet to be elucidated (EPUAP, 2009; NPUAP, EPUAP, 2014). The prevalence of pressure ulcers (PUs) is an established quality indicator in health care (Gunningberg et al., 2013). PUs present a major health challenge worldwide: they affect large numbers of people and result in considerable health system expenditure. Hospital-acquired PUs (HAPUs) significantly increase healthcare costs.

Corresponding author: Andrea Pokorná, Department of Nursing, Faculty of Medicine, Masaryk University, Kamenice 753/5, Brno, Czech Republic; e-mail: apokorna@med.muni.cz.
The increased costs are primarily due to prolonged hospitalization. Studies have shown that the development of a PU independently increases the length of a patient's hospital stay, associated with an increased incidence of nosocomial infections and other complications (Spetz et al., 2013). International studies have reported PU prevalence ranging from $4.3 \%$ to $30.8 \%$ (Tannen et al., 2009; Kottner et al., 2010; VanDenKerkhof et al., 2011; Vanderwee et al., 2011; Moore, Cowman, 2012). It is important to emphasize that variations in the type of data collected and methods used during collection make valid study comparisons difficult. The reality in clinical settings has shown that the collection of data is often made without any systematic, on-going and validated PU registration system. In addition, estimations of the incidence and prevalence of PUs will most often be an academic and time-consuming exercise, leading to imprecise estimates based on subjective data. However, the results of PU prevalence and incidence studies can be used to raise awareness, to reduce PU occurrence, and to improve clinical practice 
(International guidelines. PU Prevention: Prevalence and Incidencein Context, 2009). Unsystematic data collection is most often the case, both nationally andinternationally. Numerical data is, generally, noncomparable across local and national boundaries, as the reported data is often collected using different criteria (patient and academic). This situation is also true for the Czech Republic, where the incidence or prevalence measurement of PUs is mostly made at local level with no standardisation. Nowadays, in the Czech Republic there are two electronic tools which many health care providers work with: the Prevalence System, realised by the National Reference Centre, to which quality managers from ten hospitals contribute, and the Incidence System, part of the Central System of Adverse Event Reporting, whereby data from approximately 86 hospitals is collected. Neither of these tools covers all inpatient settings. As a result, a project aiming to establish a new national PU register was started in May 2015. The logical first step of the project was to evaluate the existence of national registers abroad and, in particular, to map the data that is collected and analysed there and how this is used to improve the quality of care. Although reporting to the local adverse incident report system is mandatory, underreporting is likely and lower grade/stage PUs may be under-represented. A good methodological framework would be very helpful in gathering more precise data. It has been clinically proven that programmes to reduce PU occurrence should ideally include data collection systems that can provide information for clinical audit and prevalence/incidence studies. Appropriate training and testing are required for all assessors and data recorders (International guidelines. PU Prevention: prevalence and incidence in context, 2009). According to an international consensus focusing on cost effective wound management (International consensus: Making the case for cost-effective wound management. Wounds International, 2013) data collection is often sporadic and, when it is collected, poor or inconsistent methodology can make metaanalysis difficult. Data regarding clinical efficacy and effectiveness may be limited or unavailable. Financial data may be based on measurements that do not provide a true indication of cost. Thus, all of the above reasons are convincing arguments for the reporting of PUs uniformally with appropriate methodological support. Hospital-acquired PU surveillance and prevention can save costs in hospitals and should be considered by nursing executives as a strategy to support quality outcomes (Spetz et al., 2013).
Aim

The aim of this study was to analyse published studies focused on existing registers of pressure ulcer incidence operating on national level and allowing standardized collection of data.

\section{Methods}

\section{Eligibility criteria}

Several criteria were used to select eligible studies: Original articles focused on data collection and analyses of pressure ulcers on a national level. Studies which clearly defined outcomes and/or data sets of individual assessed parameters. The exclusion criteria were: studies that dealt with local datasets of PU incidence, and studies which do not describe the dataset or the usability of data collection, abstract, articles and review published in other periods of time than those indicated, those published in non-reviewed journals.

\section{Sources}

Expert licensed databases and freely accessible databases were electronically searched and, subsequently, hand searched to obtain relevant sources (specifically the electronic databases SCOPUS and Nursing OVID, which were primarily verified as suitable and appropriate). English was selected as the search language.

\section{Search}

The search strategy was implemented via the following steps: an initial search was carried out using the keywords "pressure sore OR pressure ulcer OR bed sore OR decubitus OR pressure lesion OR pressure injury AND registry OR database" in electronic databases, followed by an independent hand search, including scanning of reference lists from other sources.

Searching was limited to sources with full text articles and reviews - published from 2010 to February 2015. The survey was not restricted to a specific care setting (articles focusing on inpatient and outpatient settings could be used).

In general, only articles focusing on the areas of data monitoring and PU registers on national level were considered or with description of dataset and data usability. Contributions that did not meet the requirements and criteria for original article (Sollaci et al., 2004) were eliminated (see study selection). The results of the search were combined into a single item set. From the results of the initial search, double citations were removed and then the titles, abstracts, 
and full texts of the retrieved articles were independently evaluated for definitive inclusion.

\section{Study selection and data analyses}

The subsequent steps involved a full text screen and an analysis of individual relevant contributions and sources by six different reviewers. Firstly, the articles were reviewed independently and then a meeting was held to reach consensus on the articles to be included in the final evaluation (all of the reviewers have academic degrees, are working in clinical practices, are members of the project team preparing the new pressure sore register in the Czech Republic, and are also authors of this article).

Exclusion criteria: the source was not an original article, did not focus on PU data collection, was not a register or database of clinical administrative data for more than one clinical setting, or was published before 2010. PRISMA Guidelines (Moher et al., 2010) were followed during the design, search and reporting stages of this review of national registers of pressure ulcers.

\section{Data extraction and quality assessment}

One author (AP) gathered data regarding registers of pressure ulcers according to the inclusion and exclusion criteria (key words, type of databases, and type of study/sources). Two authors (SS and SV) independently performed two different and parallel searches to avoid omitting relevant articles. The search strategies are shown in Figure 1. The results of these two searches were combined into a single item set. From the results of the initial search, double citations were removed and then the titles, abstracts and full texts of the retrieved articles were independently evaluated for definitive inclusion. Once completed, all authors (AP, SS, SV, LK, NM, $\mathrm{CP}$ and GŠ) verified data extraction; first, independently and then a meeting was held to reach consensus on the articles to be included in the final evaluation.

\section{Results}

Figure 1 shows the process of study selection. Initial searching identified 501 sources from the aforementioned databases (365 results in the Nursing OVID database and 136 in Scopus). Following the first screening, 162 articles from Nursing OVID and 50 from Scopus were excluded. 203 articles from Nursing OVID and 86 from Scopus were retained for title and abstract screening.

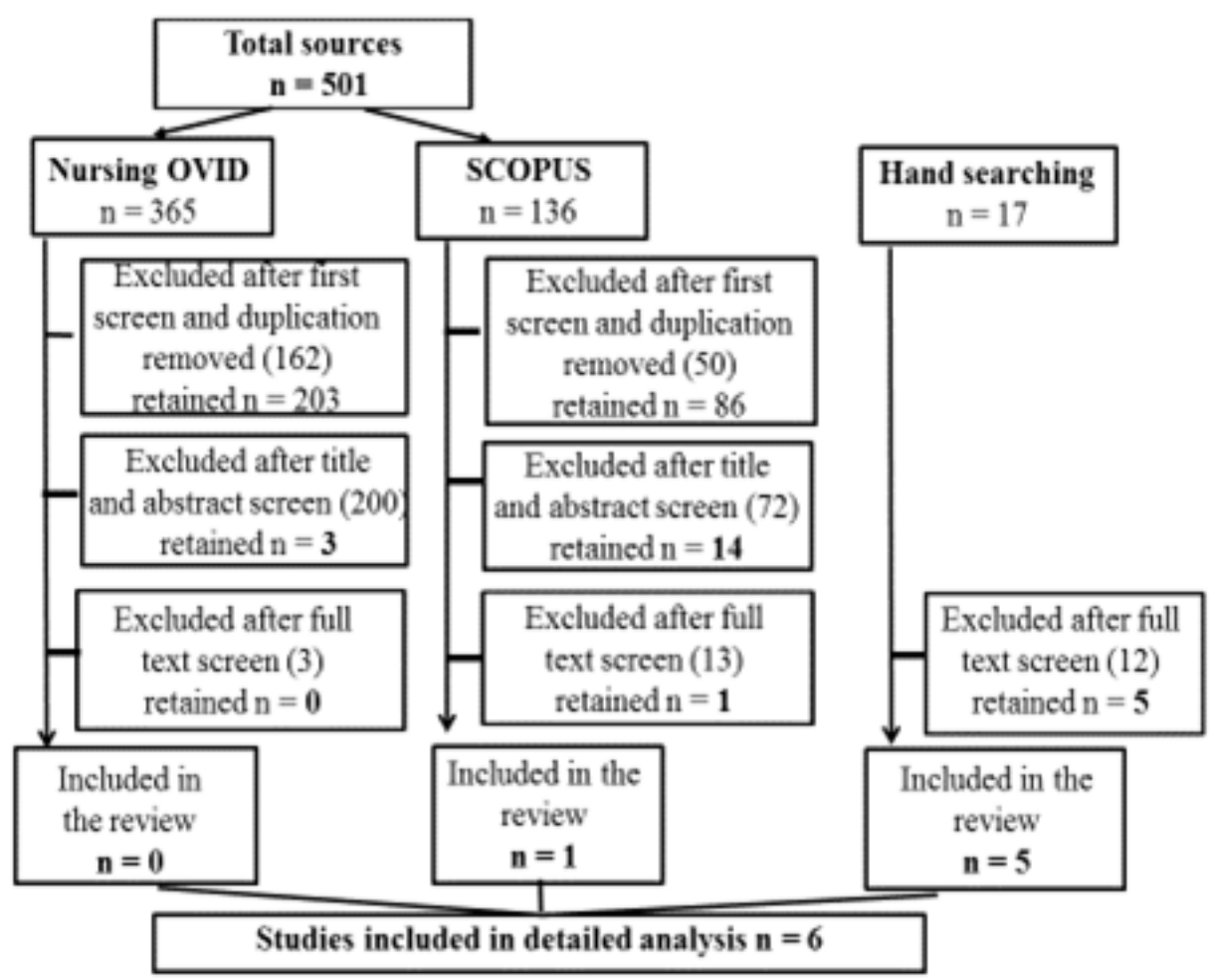

Figure 1 Flow chart - selection of studies 
After the title and abstract screening, only three relevant studies from the OVID database and 13 sources from Scopus were selected for further processing (all of which focused on the issue of PUs and their monitoring in general) and were subjected to content analysis. Using the inclusion and exclusion criteria, a further 15 articles were excluded. Thus, from these 16 sources only one fulfilled the inclusion criteria for detailed analysis (15 were excluded after full screening). Finally an independent hand search, including scanning of reference lists from other sources, was performed. In total, 17 sources were identified and, after abstract and full text screening, five were selected for detailed analysis.

This study finally included six relevant papers that focused on the monitoring of PU incidence and existing national registers, from which two of them included a description of the data that had been collected and four of them were aimed at extending information about the same register (RUT), using different methods of analysis and usability of the data (Table 1).

Table 1 Summary of selected studies dealing with the monitoring of PU on central and standardized level

\begin{tabular}{|c|c|c|c|}
\hline $\begin{array}{l}\text { Author } \\
\text { (year) }\end{array}$ & Aim & Methods & Results \\
\hline $\begin{array}{l}\text { Rosengren, } \\
\text { Höglund, } \\
\text { Hedberg* } \\
\text { (2012) }\end{array}$ & $\begin{array}{l}\text { To evaluate and describe nurses' } \\
\text { experiences of a recently implemented } \\
\text { quality register. }\end{array}$ & $\begin{array}{l}\text { Qualitative } \\
\text { content } \\
\text { analysis }\end{array}$ & $\begin{array}{l}\text { Strategies concerning organizational structure } \\
\text { and committed leadership could increase the } \\
\text { usefulness of knowledge systems on all } \\
\text { levels, which could enable continuous } \\
\text { learning and quality improvement in health } \\
\text { care. }\end{array}$ \\
\hline $\begin{array}{l}\text { Kim, Park } \\
(2012)\end{array}$ & $\begin{array}{l}\text { Structured analysis of functionality of } \\
\text { data entry templates in the hospital } \\
\text { system - for clinical decision making. }\end{array}$ & $\begin{array}{l}\text { Qualitative } \\
\text { analysis }\end{array}$ & $\begin{array}{l}\text { The clinical data models and structured data } \\
\text { entry templates developed in this study were } \\
\text { useful in supporting clinical decision making } \\
\text { on pressure ulcer wound management. }\end{array}$ \\
\hline $\begin{array}{l}\text { Öien, } \\
\text { Forssell } \\
(2013)^{*}\end{array}$ & $\begin{array}{l}\text { Analysis of the Swedish Registry RUT in } \\
\text { connection with antibiotic treatment of } \\
\text { non-healing wounds to verify the cost } \\
\text { benefits of data collection in wound } \\
\text { management. }\end{array}$ & $\begin{array}{l}\text { Quantitative } \\
\text { analysis }\end{array}$ & $\begin{array}{l}\text { The register and data collection has positive } \\
\text { effect on treatment - healing time and } \\
\text { antibiotic treatment decreased significantly } \\
\text { during } 3 \text { years after launch of RUT. }\end{array}$ \\
\hline $\begin{array}{l}\text { Öien, } \\
\text { Åkesson, } \\
\text { Forssell } \\
(2013)^{*}\end{array}$ & $\begin{array}{l}\text { To evaluate the possibility to assess } \\
\text { Quality of life in patients with hard-to- } \\
\text { heal ulcers using data from registry (from } \\
\text { baseline through healing and at follow-up } \\
6 \text { months after healing). }\end{array}$ & $\begin{array}{l}\text { Mixed } \\
\text { prospective } \\
\text { study }\end{array}$ & $\begin{array}{l}\text { The results from EQ-5D did not add } \\
\text { consistent information to RUT; therefore, this } \\
\text { questionnaire was not included in the registry. }\end{array}$ \\
\hline $\begin{array}{l}\text { Öien, Weller } \\
(2014)^{*}\end{array}$ & $\begin{array}{l}\text { Analysis of the Swedish Registry (RUT) } \\
\text { focusing on the length of treatment of } \\
\text { non-healing wound and possibility to } \\
\text { share data internationally. }\end{array}$ & $\begin{array}{l}\text { Quantitative } \\
\text { analysis }\end{array}$ & $\begin{array}{l}\text { The results from the Swedish registry } \\
\text { demonstrate the remarkable potential of RUT } \\
\text { as a guarantee to improve health outcomes } \\
\text { nationwide and internationally, namely in a } \\
\text { significant reduction of healing time and } \\
\text { health costs }\end{array}$ \\
\hline $\begin{array}{l}\text { Öien RF, } \\
\text { Forsell H, } \\
\text { Tennvall GR. } \\
(2015)^{*}\end{array}$ & $\begin{array}{l}\text { Analysis of the wound management in } \\
\text { relation to the cost of treatment of non- } \\
\text { healing wounds. }\end{array}$ & $\begin{array}{l}\text { Quantitative } \\
\text { analysis }\end{array}$ & $\begin{array}{l}\text { Treatment costs for the management of hard- } \\
\text { to-heal ulcers can be reduced with well- } \\
\text { developed treatment strategies resulting in } \\
\text { shortened healing times as shown in RUT. }\end{array}$ \\
\hline
\end{tabular}

\footnotetext{
*Note: Sources dealed with the same national registry (RUT). One source presents a description of the register while the others assess its accuracy and efficiency with regard to different topics (quality of life of patients, economic burden and use of antibiotics, and the possibility of sharing and using the data set from the register at an international level).
}

\section{Discussion}

This literature review was aimed at identifying the existence of national registers of pressure ulcers (PUs) which allowed standardized data collection for more than one hospital or community care facility, describe dataset and evaluate their usability. Of the total number of full text screen sources, five related to one specific national register focusing on the incidence of non-healing wounds in general, including bedsores, (Rosengren et al., 2012; Öien and Forssell, 2013; Öien et al., 2013; Öien et al., 2014, Öien et al., 2015). According to PRISMA methodology, they were not counted as only one 
source (in terms of duplicity of sources) rather as sources which expanded information concerning the same Registry of ulcer treatment (hereinafter referred to as the RUT). The following text will describe this first register (RUT) followed by information from other secondary analyzed sources. The authors are aware that some of the data referred to in the discussion section does not relate directly to pressure sores. However, it provides a comprehensive insight into the only functional register of chronic wounds operating at a national level.

As mentioned above, a detailed analysis of the available sources (Table 1) revealed that only one national register relating not only to decubitus but also to other types of non-healing wounds has existed in Sweden since May 2009. The ambition of the Swedish register - known as the Registry of Ulcer Treatment (RUT) - is to collect data on non-healing wounds, symptoms, treatment interventions, and their outcomes in order to provide a continuous systematic evaluation of medical practice.

In 2013, Öien and Forssel published the results of a statistical analysis of the RUT in connection with data collection and with antibiotic treatment of nonhealing wounds to verify the cost benefits of data collection in wound management (Öien, Forssell, 2013). Basic information about the data contained in the register was found after a hand search of the bibliography of the paper (Öien, 2009). The register monitors a large amount of data on patients with nonhealing wounds and data entry is made in two phases.

Initial registration is usually carried out during first contact with the patient and it is used to assess nonhealing wounds, and to determine diagnosis and optimum treatment. The second registration is used for an evaluation of the efficacy of treatment, recording of therapeutic approaches in wound management, and noting of adverse events (e.g., amputations, infection, etc.).

During the first registration of the patient in the system, basic variables are recorded: social security number, gender, age, primary diagnosis, profession or former profession, smoking, customs and habits, marital status, number of children, mobility, exercise habits and body mass index. To ensure continuity of care, it is also mandatory to indicate the name of the attending nurse who is responsible for the care of the non-healing wound, and to register the patient in the RUT. Follow-up information relates to the local symptomatology of non-healing wounds. History focusing on the incidence of deep vein thrombosis, varicose veins and vascular surgical interventions is also recorded. Other monitored information includes current or previous concomitant diseases (comorbidities), and history of recurrent venous ulcers and their location.

Monitored and recorded input parameters of wounds, including their objective evaluation, wound age, location, size objectified by measurement using a digital planimeter - Visitrak, pain, and treatment of pain using analgesics, and antibiotic use in connection with the treatment of wounds are recorded, as are test results of arterial blood circulation in the lower extremities. Finally, information is recorded on wound management, with an emphasis on the selection of therapeutic covering materials, care of the area surrounding the wound, and treatment of edema. Clinical symptoms are also photographically documented and recorded in the database. The second registration (mostly used for outcome evaluation purposes), includes data such as date and time of treatment, estimated number of weekly dressing changes throughout healing, changes in wound healing, compression therapy, treatment with antibiotics, pain relief, and the most frequently used dressing material.

Also reported are the results of educational activities aimed at smoking cessation, changes in physical activities, exercise, and dietary changes. The occurrence of "adverse" events and the impact of treatment such as amputation, venous or arterial surgery, pinch grafting, and death are also reported. The prepared dataset within this database is very detailed. The authors of this review are convinced that if an attempt were made to implement it in its entirety into clinical practice in the Czech Republic, there would be a genuine risk of over burdening health workers, and a subsequent reluctance to report data, which could result in incomplete data collection. The authors also believe that the implementation of such a register tracking data to this extent would not be useful or expedient.

On the other hand, it is necessary to recognize that most of the information is very important and useful for longitudinal monitoring, and is mostly collected in the form of local rather than comprehensive surveys. For the process of preparing a new register of PU incidence in the Czech Republic, it is important to record initial evaluations and at least output assessment using objective scales and evaluation tools for both assessment of the overall condition of the patient and evaluation of local findings. Equally important is feedback for reporting workplace and methodological support for uniform data entry. Clearly, uniform assessment of the wound, and subsequent reporting, are a prerequisite for valid data. The foundation of healthcare management of patients with non-healing, chronic 
wounds requires accurate evaluation followed by selection of an appropriate therapeutic strategy. Assessment of non-healing, chronic wounds in clinical practices in the Czech Republic is not standardized. In 2015, Pokorná and Leaper (2015) published a study to analyze the procedures and methods used to assess non-healing wounds in inpatient facilities in the Czech Republic. The results of this research have corroborated the suspicion of inconsistencies in procedures used by general nurses for assessment of non-healing, chronic wounds. However, the situation was found to be more positive with regard to the evaluation of basic/fundamental parameters of wounds (i.e., size, depth and location of wounds) compared with the evaluation of more specific parameters (e.g., exudate or signs of infection) and this should be taken into consideration when establishing a new register. Systematic work with future users of the register is fundamental, as confirmed by the publication of the team of authors Rosengren et al. (2012). Their qualitative study focused on nurses' experiences with the implementation of the RUT in Sweden, which is described in detail in the aforementioned papers, published in 2009 and 2013. It was a study validating the implementation process of the RUT. The study involved two Swedish hospitals with a specialization in internal medicine and orthopedic care focusing on care of elderly patients aged over 70 . In total, eight nurses working at the bedside of elderly patients were given unstructured interviews. Questions focused primarily on nurses' experience with implementing the register, on how to improve working with the register in everyday practice, and on satisfaction with the instructors and educators who provided nurses with the necessary training to implement the register. Data collection lasted from December 2009 to April 2010. Interviews were analyzed by qualitative content analysis. One of the objectives of the study was to help other organizations in the establishment and implementation of similar registers. The conclusion of the study was that the implementation process should not be too complicated and must be sustainable at both the managerial and employee level. Nurses stressed the need to change their "mindset" in order to improve access to changes and improve implementation of the register. Nurses also indicated a need for increased cooperation with patients and their family members. Use of the register was positively reflected in work planning and in the possibility of using evidence-based practice. Nurses actively required support and development of knowledge and skills because of the new tasks in their daily duties. The authors of the new Czech PU register believe it is very important that an appropriate pressure ulcer risk assessment scale with high predictive validity be a monitored parameter (Š́teková, Žiaková, 2014; Šáteková et al., 2015).

The paper did not deal with each component of the register or the extent of observed data (as described above). However, this information is important in terms of possible implementation of the emerging new register of incidence of PUs in the Czech Republic and, thus, we have included a section in this research. In connection with the Swedish register, Öien et al. (2013) also published a quantitative survey focusing on the evaluation of quality of life of patients with hard-to-heal wounds and/or non-healing wounds through the EQ-5D questionnaire. The authors use the concepts "hard-to-heal wound" and "non-healing wound", which have little connotative difference (they have the same scientific meaning) and, therefore, in our text we will use the term "nonhealing wound". Patients were observed from the beginning of treatment of their non-healing wounds and over the six months following termination of treatment. The sample consisted of fifty patients of different ages and gender with non-healing wounds of different etiology. The aim was to determine the usefulness of the questionnaire as a tool for evaluating quality of life and suitability for inclusion in the RUT. The study found a significant difference in quality of life between patients with currently open non-healing wounds and those with already healed wounds $(p=0.02)$. Age, gender and duration of treatment of non-healing wounds do not statistically affect quality of life of patients. The study, therefore, confirms that quality of life in patients with healed non-healing wounds improves. Although the simplicity of the EQ-5D questionnaire is an advantage and it can be used in clinical practice, it has not yet been included in the Swedish register. Similarly, the authors of the new Czech register of PU incidence do not plan to implement tools for evaluating patient quality of life. From the point of view of international collaboration, it is interesting to consider the work of Öien and Weller (2014), who, in 2014, published a contribution offering reflections on the application of positive treatment results from the RUT in Australia. They do not primarily focus on PUs, but rather on the fact that chronic venous diseases are increasingly considered a priority for healthcare in an international context and that the prevalence of venous ulcers is increasing due to the increased prevalence of venous disease, diabetes and obesity.

The results of the RUT show remarkable potential and guarantee improvements in health care at a national and international level, reducing the healing time of non-healing wounds and, thereby, reducing 
the cost of treatment. Öien and Weller wonder whether this is possible even in Australia, where a meaningful comparison of data is required to improve clinical practice in the treatment of non-healing wounds. The Swedish register has clearly shown that measured results can have a significant impact on the delivery of health care. On an individual scale, the patient can expect clearer information about treatment outcomes and better care from professionals whose work is regularly evaluated. This corresponds with previously presented information (International guidelines. Pressure ulcer prevention: prevalence and incidence in context, 2009; Spetz et al., 2013).

The measurement of results requires consistent accountability of health care providers, not only for the care of non-healing wounds. Nowadays, in Australia the problem of non-healing wounds, their root causes, and the need for active treatment, are being actively addressed. Thus, the ambition is to use the Swedish experience with wound management at a national level, with emphasis on diagnosis, documentation and treatment of non-healing wounds. The information presented is an important argument for the preparation of a new register of PU incidence in the Czech Republic. The authors of this literature review have been in personal contact with the author of the Swedish RUT (Dr. Öien). They have shared information about the benefits and risks of creating a new dataset for PUs. It should be noted that despite the existence of a Swedish register other prevalence studies on decubitus lesions have been implemented in Sweden (Gunningberg et al., 2013). These studies may have the potential for validation of data obtained from the register, but must respect the same methods of data collection as the RUT.

The most recent study making reference to the RUT was published in 2015 (Öien et al., 2015). It presents an analysis of the costs associated with the treatment of non-healing wounds in connection with the existence of the RUT. The analysis of resources and costs of local treatment of non-healing wounds was based on data recorded in the RUT from 2009 to 2012. The aim of this analysis was to quantify the potential savings due to shortening treatment time of non-healing wounds. Frequency of weekly dressing changes in the database is between 1.4-1.6 per week. The cost of treatment of non-healing wounds can be reduced only with a well-chosen therapeutic strategy, leading to a shortening of treatment time. The total healing time has been reduced since 2009 by $38 \%$. In 2009 , the treatment of non-healing wounds "per patient" was estimated at 38,223 Swedish Krona. By 2012, the total cost of treatment per patient had decreased to 20,496 Swedish Krona. In a similar Swedish study from 2006, the amounts are much higher, but the calculation was performed in the framework of weekly treatment (Tennvall et al., 2006).

The final study that met our established criteria for inclusion in this research does not dispose of information from a common registry. Instead, it uses administrative data from patient records and presents interesting information on the basic data set, which is important for assessing both the incidence of PUs and the choice of appropriate therapeutic strategies. In 2012 Korean authors Kim and Park (2012) published the development of a data set for the computer program SNOMED CT, designed for clinical practice in community care at a national level. Its aim was to unify and support clinical decision-making in wound management of pressure sores. The data file was designed to help health care professionals to assess PUs, plan treatment, and evaluate the effectiveness of wound care in accordance with guidelines for wound management.

The selection of observed parameters of the data set was made after studying the clinical guidelines for the treatment of decubitus from the following three organizations - NPUAP (National Pressure Ulcers Advisory Panel), WOCN (Wound Ostomy and Continence Nurses Society) and RNAO (Registered Nurses Association of Ontario). The validity of data file content was evaluated by three home-care specialists (Figure 2). This contribution is an important source of information for the creation of a dataset for a new register of PU incidence in the Czech Republic. It was also the reason for adopting NPUAP categorization, rather than EPUAP categorization, for PUs in the new Czech data set.

From the available electronic resources, it is evident that the issue of registers in health care is, in general, not sufficiently discussed - not only in relation to pressure sores. The lack of studies in this field was also revealed by our research. One reason may be that they simply do not exist. On the other hand, it is realistic to assume that register information (in the context of wound management) is published at alocal level in particular countries and, thus, cannot be found on international databases. With regard to the lack of resources in the database, a logical follow-up step is a feasibility study by official representatives of collaborating organizations with the EWMA (European Wound Management Association) and the EPUAP (European Pressure Ulcers Advisory Panel), in order to determine the existence of registers focusing on the care of patients with non-healing wounds. 
It can be assumed that registers exist in other countries, but that this information is not available on electronic databases, hence the aforementioned survey. Resulting from analysis of the foreign registers we did discover, the National Register of PU incidence in the Czech Republic is being prepared with the aim of finding a balance between minimizing the burden on healthcare personnel and maximizing data yield. The aim is to create a socalled "minimal" dataset (input and output evaluation of the patient), including a methodology for evaluation of the patient and local findings so that the incidence of reporting of PUs is effective and the results of analyses of data from the register are applicable to clinical practice.

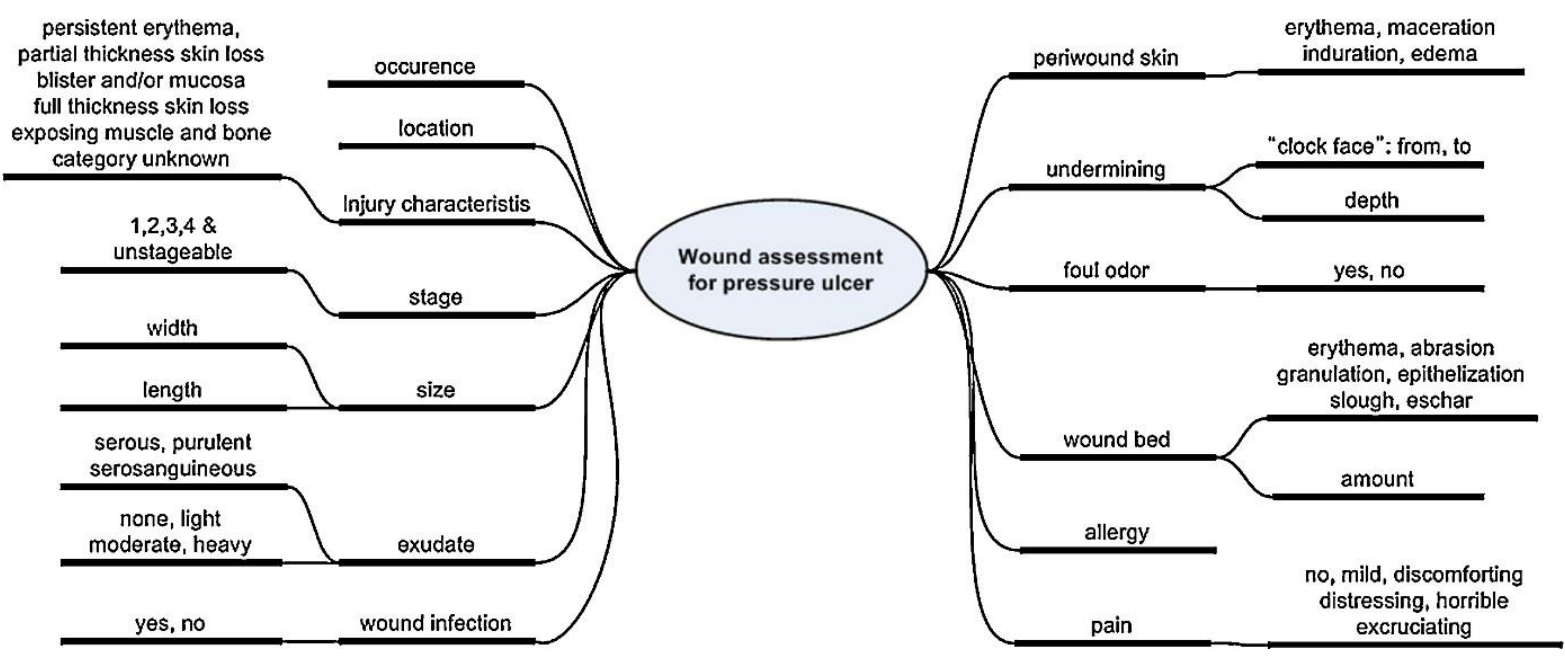

Figure 2 Monitored parameters within the Korean dataset (Kim, Park, 2012)

\section{Conclusion}

Data provided from the study of registers and concrete data sets about PUs is limited. There are only two sources which present information on the data about chronic wounds, including PUs, that should be collected in standardized manner. After detailed inspection of the articles it appears that the information derived from the studies could provide a useful picture of the data items that should be collected and at what time during the treatment period (initial and final assessment of the patients and local symptomatology of the wound/pressure sore) this should be done. The significance of the existence of the register and the active use of data in practice is, for wound management, clear, as demonstrated by the results of the Swedish publications listed - either there are real savings in the system of wound healing or greater continuity of care is ensured for patients with non-healing wounds.

\section{Implications for clinical practice}

Almost 20 years after the declaration of the importance of uniform reporting of PUs made by the EPUAP, there is still a lack of focus on uniform data collection. On looking through the research literature, a number of guidelines emerge that can be used to facilitate effective collection of data regarding PUs. These guidelines are, for the most part, consistent regardless of the goal (e.g., category or size of PU). Nevertheless, their application in daily practice might be affected by multiple factors. In addition, data collection is still largely inconsistent and influenced by local know-how and requirements of management in a particular hospital or healthcare facility. Future research should be oriented towards the questions of which activities should be a part of the screening for global assessment, registration, and uniform data collection of PUs at a national or international level. How can nurses be taught to assess PUs accurately? What are the main barriers for accurate assessment and what are the reasons for the lack of records and under reporting on pressure ulcers in clinical practice - despite their significant economic burden to health care systems?

\section{Limitations of study}

The main limitation to this literature review is the small number of articles found on PU registers. Other limitations: our study only includes material published in English and publicly available on databases. 


\section{Ethical aspects and conflict of interest}

All bibliographical sources used have been cited. The author declares that the present study involves no conflicts of interest.

\section{Acknowledgements}

This study was supported by the Ministry of Health of the Czech Republic, grant no. 15 - 29111A with title - "The register of decubitus ulcers - Integration strategy for monitoring and preventive interventions on the national level". All rights reserved.

\section{Author contributions}

Conception and design of the literature review (AP, SS, VS), data analysis and interpretation (AP, SS, VS, LK, PC, GŠ and MN), manuscript draft (AP, SS, VS), critical revision of the manuscript (AP), final approval of the manuscript (AP, SS, VS).

\section{References}

European Pressure Advisory Panel, National Pressure Ulcer Advisory Panel. Prevention and treatment of pressure ulcers: quick reference guide. Washington DC: National Pressure Ulcer Advisory Panel; 2009.

Gunningberg L, Hommel A, Bååth C, Idvall E. The first national pressure ulcer prevalence survey in county council and municipality settings in Sweden. Journal of Evaluation in Clinical Practice. 2013;19(5):862-867.

International consensus: Making the case for cost-effective wound management. Wounds International. 2013. [cited 2015 Sep 18]. Available from: http://www.woundsinternational.com/other-

resources/view/international-consensus-making-the-case-forcost-effective-wound-management

International guidelines. $P U$ prevention: prevalence and incidence in context. A consensus document. London: MEP Ltd., 2009. [cited 2015 Sep 18]. Available from: http://www.woundsinternational.com/media/issues/64/files/co ntent_24.pdf

Kim HY, Park HA. Development and evaluation of data entry templates based on the entity-attribute-value model for clinical decision support of pressure ulcer wound management. International Journal of Medical Informatics. 2012;81(7):485-492.

Kottner J, Dassen T, Lahmann N. Prevalence of deep tissue injuries in hospitals and nursing homes: two cross-sectional studies. International Journal of Nursing Studies. 2010;47(6):665-670.

Moore Z, Cowman S. Pressure ulcer prevalence and prevention practices in care of the older person in the Republic of Ireland. Journal of Clinical Nursing. 2012;21(34):362-371.

Moher D, Liberati A, Tetzlaff J, Altman DG, PRISMA Group. Preferred reporting items for systematic reviews and meta-analyses: the PRISMA statement. International Journal of Surgery. 2010;8(5):336-341.

National Pressure Ulcer Advisory Panel, European Pressure Ulcer Advisory Panel and Pan Pacific Pressure Injury
Alliance. Prevention and treatment of pressure ulcers: quick reference guide. Haesler E (Ed.). Cambridge Media: Osborne Park, Western Australia; 2014.

Öien RF. RUT - a winning concept for both patients and the health care sector. EWMA Journal. 2009;9(2):41-44.

Öien RF, Åkesson N, Forssell H. Assessing quality of life in patients with hard-to-heal ulcers using the EQ-5D questionnaire. Journal of Wound Care. 2013;22(8):442444;446-447.

Öien RF, Forssell HW. Ulcer healing time and antibiotic treatment before and after the introduction of the Registry of Ulcer Treatment: an improvement project in a national quality registry in Sweden. BMJ Open. 2013;3(8):e003091.

Öien RF, Forsell H, Ragnarson Tennvall G. Cost consequences due to reduced ulcer healing times - analyses based on the Swedish Registry of Ulcer Treatment. International Wound Journal. 2015. doi: 10.1111/iwj.12465. [Epub ahead of print]

Öien RF, Weller CD. The Swedish national quality Registry of Ulcer Treatment (RUT): Howcan 'RUT' in form outcome measurement for people diagnosed with venous leg ulcers in Australia? Wound Practice and Research. 2014;22(2):74-77.

Pokorná A, Leaper D. Assessment and documentation of nonhealing, chronic wounds in inpatient health care facilities in the Czech Republic: an evaluation study. International Wound Journal. 2015;12(2):224-231.

Rosengren K, Höglund PJ, Hedberg B. Quality registry, a tool for patient advantages - from a preventive caring perspective. Journal of Nursing Management. 2012;20(2):196-205.

Sollaci LB, Pereira MG. The introduction, methods, results, and discussion (IMRAD) structure: a fifty-year survey. Journal of the Medical Library Association. 2004;92(3):364371.

Spetz J, Brown DS, Aydin C, Donaldson N. The value of reducing hospital-acquired pressure ulcer prevalence: an illustrative analysis. Journal of Nursing Administration. 2013;43(4):235-241.

Šáteková L, Žiaková K. Validity of Pressure Ulcer Risk Assessment Scales: review. Central European Journal of Nursing and Midwifery. 2014;5(2):85-92.

Šáteková L, Žiaková K, Zeleníková R. Predictive validity of the Braden scale, Norton scale and Waterlow scale in Slovak Republic. Central European Journal of Nursing and Midwifery. 2015;6(3):283-290.

Tannen A, Dietz E, Dassen T, Halfens R. Explaining the national differences in pressure ulcer prevalence between the Netherlands and Germany - adjusted for personal risk factors and institutional quality indicators. Journal of Evaluation in Clinical Practice. 2009;15(1):85-90.

Tennvall GR, Hjelmgren J, Öien RF. The cost of treating hard-to-heal venous leg ulcers: results from a Swedish survey. World Wide Wounds. [cited 2015 Sep 18]. Available from: http://www.worldwidewounds.com/2006/november/Tennvall/ Cost-of-treating-hard-to-heal-venous-leg-ulcers.html Vanderwee K, Defloor T, Beeckman D, Demarré L, Verhaeghe S, Van Durme T, Gobert M. Assessing the adequacy of pressure ulcer prevention in hospitals: a nationwide prevalence survey. BMJ Quality \& Safety. 2011;20(3):260-267.

VanDenKerkhof EG, Friedberg E, Harrison MB. Prevalence and risk of pressure ulcers in acute care following implementation of practice guidelines: annual pressure ulcer prevalence census 1994-2008. Journal for Healthcare Quality. 2011;33(5):58-67. 